This is the peer reviewed version of the following article:

Honzíček, J. and Vinklárek, J. ( 2017), Chemical curing of alkyd resin catalyzed by benzoylferrocene: Performance, kinetics, and thickness effects. J. Appl. Polym. Sci., 135, 46184. doi: 10.1002/app.46184

This article may be used for non-commercial purposes in accordance With Wiley-VCH Terms and Conditions for self-archiving".

This postprint version is available from https://hdl.handle.net/10195/72672 


\title{
Chemical Curing of Alkyd Resin Catalyzed by Benzoylferrocene: Performance, Kinetics and Thickness Effects.
}

\author{
Jan Honzíček, ${ }^{1}$ Jaromír Vinklárek ${ }^{2}$
}

${ }^{1}$ Institute of Chemistry and Technology of Macromolecular Materials, Faculty of Chemical Technology, University of Pardubice, Studentská 573, 53210 Pardubice, Czech Republic

${ }^{2}$ Department of General and Inorganic Chemistry, Faculty of Chemical Technology, University of Pardubice, Studentská 573, 53210 Pardubice, Czech Republic

Correspondence to: J. Honzíček (E-mail: jan.honzicek@upce.cz)

\begin{abstract}
Catalytic properties of benzoylferrocene, as a representative of cobalt-free drier, was investigated on alkyd resin modified with soybean oil. Mechanical tests, performed on alkyd films, revealed promising activity at low metal concentrations. A detailed analysis of time resolved infrared spectra was used for in-depth investigation of chemical curing in the films. The experiments, performed in transmission mode, enabled determination of kinetic parameters for the autoxidation process. Effects of film thickness was investigated using ATR-technique.
\end{abstract}

\section{INTRODUCTION}

Alkyd resins, modified with drying and semidrying vegetable oils, are established as a significant group of air-drying paints and inks used in modern organic coatings and graphic arts (Fig. 1).$^{1-3}$ After solvent evaporation, the alkyd film is very soft and the hardening is based on the cross-linking process of the fatty acid tails, which occurs in the presence of air-oxygen. The chemical drying is generally a very slow process at ambient temperature giving the paint film with a very low final hardness. Nevertheless, the use of metal catalysts, so-called driers, considerably reduces the drying time and improves physical properties of the final polymeric film. ${ }^{4,5}$ Although cobalt carboxylates (e.g. cobalt(II) 2-ethylhexanoate) are very powerful alkyd driers and well established in paint producing industry, there is increasing global demand for their replacement due to harmful effects on human health. ${ }^{6,7}$ The quest is stimulated by European REACH (Registration, Evaluation, Authorisation and Restriction of Chemicals) legislation since they have been classified as "CMR2-Reprotoxic" by the Cobalt REACH Consortium. Recently, several manganese, ${ }^{8,9}$ iron ${ }^{10-13}$ and vanadium-based driers, ${ }^{14-16}$ suitable for alkyd binders, have been described in literature and some of them are already commercially available. Nevertheless, most of the alternatives still suffers several disadvantages (e.g. low solubility in formulation, intense coloration). 


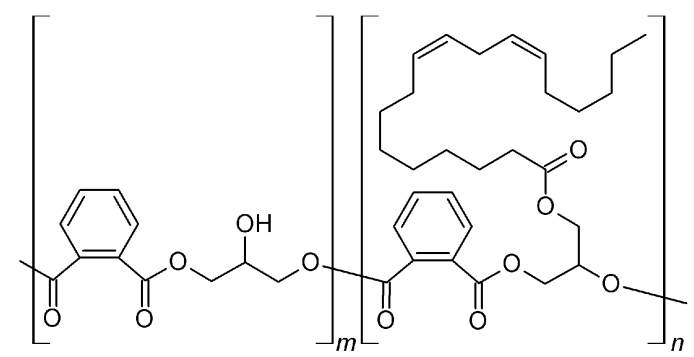

FIGURE 1 Simplified Chemical Structure of Phthalic-type Alkyd Binder.

Chemical drying of alkyd binders, catalyzed by transition metal compounds, is based on autoxidation of fatty acid tails, which involves a complex set of chemical processes. Mechanism of the drying has been extensively studied on liquid model compounds (e.g. unsaturated fatty acid esters, alkyl hydroperoxides) by various experimental techniques. ${ }^{13,17-20}$ The main steps of the radical chain process are outlined in Fig. 2. Briefly, the autoxidation is a radical chain process that is initiated by abstraction of activated hydrogen atom from double allylic methylene group that could be realized at elevated temperate or photochemically. The appeared alkyl radical $\left(R^{\bullet}\right)$ readily reacts with air oxygen to give peroxyl radical $\left(\mathrm{ROO}^{\circ}\right)$ that plays an important role in the propagation step. It abstracts hydrogen atom from another fatty acid chain $(\mathrm{RH})$ to give primary oxidation product $(\mathrm{ROOH})$ and further alkyl radical $\left(\mathrm{R}^{\circ}\right)$. In presence of metal driers, the chain reaction is usually not initiated by aforementioned dissociation but with peroxyl radicals (ROO') appearing through decomposition of hydroperoxides (ROOH) present in trace amounts in crude alkyd resins. The main role of metal-based driers lies in catalysis of hydroperoxide decomposition since the primary oxidation product is kinetically stable at ambient temperature. The decomposition proceeds as a cyclic one-electron redox process giving alkoxyl $\left(\mathrm{RO}^{\circ}\right)$ ) and peroxyl radicals $\left(\mathrm{ROO}^{\circ}\right)$. The three-dimensional polymeric network is then formed through addition of relevant radicals $\left(\mathrm{R}^{\bullet}, \mathrm{RO}^{*}, \mathrm{ROO}{ }^{\circ}\right)$ to conjugated double bond systems appearing upon the autoxidation process. The crosslinks are also formed by recombination reactions within termination step. ${ }^{4,5,18}$

Major drawback of the simplified systems, used as models for alkyd coating, is that they give only approximate insight into kinetics of the drying process since effects of viscosity development and oxygen diffusion are neglected although they play a very important role. A direct way of monitoring the chemical changes on bulk alkyd films is given by time-resolved $I R^{12}$ and Raman spectroscopy. ${ }^{21}$ Development of the mechanical properties has been followed on a quartz crystal microbalance. ${ }^{22}$ Spatial (i.e. in depth) effects on the drying of alkyd binders has been studied by Confocal Raman Microscopy ${ }^{23,24}$ and NMR Imaging. ${ }^{25,26}$

This study is aimed in detailed monitoring of chemical drying by time-resolved IR spectroscopy. The classical transmission technique is used for kinetic studies while the experiments on Attenuated Total Reflectance (ATR) crystal for investigation of the "in depth" effects. All experiments are performed on solvent-borne alkyd binder cured with benzoylferrocene ( $\mathbf{B z} \mathbf{z}_{\mathbf{1}} \mathbf{F c}$, Fig. 3), which is the most powerful ferrocene-based drier. ${ }^{13,27,28}$ 


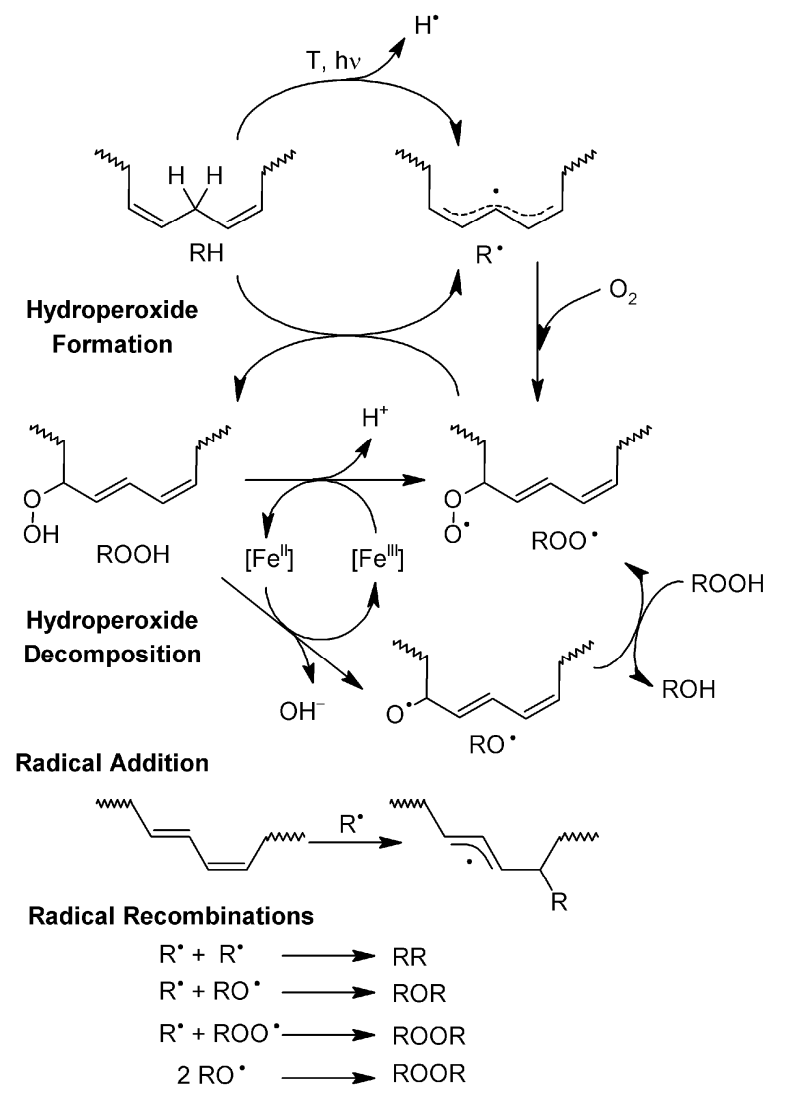

FIGURE 2 Chemical Drying of Alkyd Binders Catalyzed with Iron-based Drier.

\section{EXPERIMENTAL}

\section{Methods and Material}

Benzoylferrocene $\left(\mathrm{Bz}_{1} \mathbf{F c}\right)$ was prepared as described elsewhere. ${ }^{29}$ Solvent-borne phthalic-type alkyd resin modified with soybean oil CHS-Alkyd S $471 \times 60$ (S471; medium oil length, acid value $=6 \mathrm{mg}$ $\mathrm{KOH} / \mathrm{g}$ ) was supplied by Spolchemie. All reported metal concentrations are given in wt.\% based on dry matter of the alkyd resin.

\section{Preparation of Test Coatings}

$\mathrm{Bz}_{1} \mathrm{Fc}$ was treated with $100 \mu \mathrm{l}$ of DMSO. Immediately after dissolution, it was treated with $5.00 \mathrm{~g}$ of $\mathbf{S 4 7 1}$, vigorously stirred for $2 \mathrm{~min}$ to get a homogenous mixture and degassed in ultrasound bath ( $3 \mathrm{~min}$ in degas mode). The films were cast on given substrate using frame applicators with appropriate gaps.

\section{Determination of drying times}


The drying performance has been determined using a B. K. Drying Time Recorder (BYK) according to ASTM D5895-03 ${ }^{30}$ and under standard laboratory conditions $\left(T=23{ }^{\circ} \mathrm{C}\right.$, rel. humidity $\left.=50 \%\right)$. The instrument is a straight-line recorder equipped with hemispherical-ended needle ( $D=1 \mathrm{~mm})$. The films were cast on clean glass strips $(305 \times 25 \times 2 \mathrm{~mm}$ ) using frame applicator of $76 \mu \mathrm{m}$ gap. The needle was placed in horizontal direction at the beginning of the wet film and equipped with $5 \mathrm{~g}$ weight. The straight-line groove formed during $24 \mathrm{~h}$ were used for estimation of tack free time $\left(\tau_{1}\right)$ and total drying time $\left(\tau_{2}\right)$ of given formulation. During the first period of film drying $\left(t=0-\tau_{1}\right)$ the solvents are evaporated and sol-gel transition proceeds. The needle gives bold and uninterrupted line. During the second period $\left(t=\tau_{1}-\tau_{2}\right)$ the needle starts to climb over the film. It tears the layer and lefts a ragged groove. After $\tau_{2}$, no visible mark is observed on the film. ${ }^{31}$

\section{Determination of Relative Film Hardness}

Film hardness development was monitored using a Pendulum Hardness Tester (Elcometer) with Persoz type pendulum in conformity with ISO $1522{ }^{32}$ under standard laboratory conditions $\left(T=23{ }^{\circ} \mathrm{C}\right.$, rel. humidity $=50 \%)$. The method is based on registering the number of pendulum swings it takes before the amplitude of the pendulum is damped to a certain extent. ${ }^{33}$ Test films were cast on glass plates $(100 \times$ $200 \times 4 \mathrm{~mm}$ ) using frame applicator of $150 \mu \mathrm{m}$ gap and their properties were measured within 100 days. The measured values were related to the hardness of a glass standard (limit value of the pendulum test) and expressed as relative hardness. The reproducibility limit of the method is $8 \%$ of their mean value, with a $95 \%$ probability.

\section{Time-resolved infrared spectroscopy}

The infrared spectra of alkyd coatings were measured on a FTIR spectrometer iS50 (Nicolet) in the range of $4000-500 \mathrm{~cm}^{-1}$ with resolution of $2 \mathrm{~cm}^{-1}$ (32 scans per spectrum) under standard laboratory conditions $\left(T=23{ }^{\circ} \mathrm{C}\right.$, rel. humidity $\left.=50 \%\right)$. The measurements in transmission mode were done as follows. Given formulation of alkyd resin was cast on a NaCl plate $(22 \times 40 \times 6 \mathrm{~mm})$ using frame applicator of $100 \mu \mathrm{m}$ gap, placed in the spectrometer and the transmission spectra were collected each $5 \mathrm{~min}$ for 20-60 h. The effect of film thickness was estimated on a built-in all-reflective diamond ATR. Given formulation was cast on the flat sampling plate using frame applicator of appropriate gap. As the top surface of ATR crystal lays $20 \mu \mathrm{m}$ above the sampling plate, wet coating on the crystal was always 20 $\mu \mathrm{m}$ thicker than the gap of the frame applicator used. Time-resolved IR spectra were integrated using fixed two-point baseline in the region $3025-2990 \mathrm{~cm}^{-1}$ (cis- $\mathrm{C}=\mathrm{C}-\mathrm{H}$ stretch). Rate coefficients $\left(-k_{\mathrm{cH}, \max }\right)$ at the beginning of the peroxidation process were estimated as the steepest slope of the logarithmic plot of the integrated area vs. time. The error in determination of $k_{\mathrm{CH} \text {,max }}$ was less than $10 \%$ (three independent measurements for each run). The half-life of the peroxidation process $\left(t_{1 / 2}\right)$ is determined as the time, in which the integral plots reaches $50 \%$ of initial intensity. Induction times (IT) have been determined from the logarithmic plots graphically as intersection of horizontal line at 4.605 and tangential line extending the curve after knee point. The intensity of bands at 989 and $973 \mathrm{~cm}^{-1}$ was determined as the height of the band at these wavenumbers using linear baseline fixed at wavenumbers 1010 and $945 \mathrm{~cm}^{-1}$. In this case, a correction on co-solvent evaporation has to be made due to absorption band of DMSO at 1017 and $952 \mathrm{~cm}^{-1}$. For this purpose, evaporation of DMSO was followed 
on formulations of appropriate thickness without a drier and development of appropriate band was corrected by subtraction. The parameter $t_{\text {conj }}$ is defined as the time, in which plots of the band at 989 $\mathrm{cm}^{-1}$ reaches a maximum.

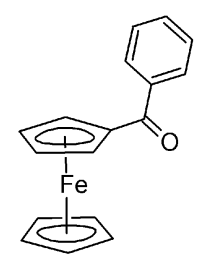

FIGURE 3 Chemical Structure of Benzoylferrocene $\left(\mathrm{Bz}_{1} \mathbf{F c}\right)$.

\section{RESULTS AND DISCUSSION}

\section{Drying Activity of Benzoylferrocene}

The evaluation of drying activity of $\mathbf{B z}_{\mathbf{1}} \mathbf{F c}$ was performed on solvent-borne alkyd resin modified with soybean oil S471, which is widely used in industry as a binder for economic primers and anticorrosive coatings. Weak solubility of $\mathbf{B z}_{1} \mathbf{F c}$ in formulation was overcame by predissolution of the drier in dimethyl sulfoxide (DMSO), which seems to be a promising candidate to replace toxic volatile solvents. ${ }^{34}$ In order to optimize dosage of the drier, mechanical properties of test coatings were examined in a range of metal concentrations $0.01-0.1 \mathrm{wt} . \%$. The optimization procedure is focused mainly on reduction of tackfree time $\left(\tau_{1}\right)$ and total-dry time $\left(\tau_{2}\right)$. The test coatings, treated with $\mathbf{B z} \mathbf{z}_{1} \mathbf{F c}$, show optimal performance at metal concentration $0.06 \mathrm{wt} . \%$ as evidenced from very fast curing at room temperature (Table 1 ). At this concentration, the test coating is total dry in $4.5 \mathrm{~h}$ and relative hardness, measured by pendulum test 100 days after application, reaches $44.2 \%$ of glass standard. The coatings with lower concentration of the drier are cured slower. Nevertheless, the concentration $0.01 \mathrm{wt} . \%$ is still suitable for common applications. At higher concentration than optimal (0.1 wt. \%), strong overdose effect is observed as evident from long tack-free time $\left(\tau_{1}\right)$. In summary, $\mathbf{B z}_{\mathbf{1}} \mathbf{F c}$ in $\mathbf{S 4 7 1}$ exhibits promising drying properties in a broader range of concentration (0.06-0.01 wt.\%) than commercial cobalt 2-ethylhexanotate. According to our previous study, the cobalt-based catalyst is highly active only at $0.1 \mathrm{wt} . \%$ ( $\tau_{1}=3.8 \mathrm{~h}, \tau_{2}=10.3 \mathrm{~h}$, $\left.\mathrm{H}_{\mathrm{rel}}=55.9 \%\right)$. At lower concentration $(0.03 \mathrm{wt} . \%)$, the total-dry time exceeds $24 \mathrm{~h} .{ }^{14}$ We note that previous study, performed on an alkyd binder modified with tall oil fatty acids (TOFA), reported lower total-dry times for formulations treated with $\mathbf{B z}_{1} \mathbf{F c}{ }^{13}$ The generally lower reactivity of the binder modified with soybean oil, used here, is owing to low content of unsaturated fatty acids and absence of rosin acids. ${ }^{3,35}$ 
TABLE 1 Drying Times, Relative Hardness of Test Coatings

\begin{tabular}{|c|c|c|c|}
\hline $\begin{array}{l}\text { Metal } \\
\text { content } \\
\text { (wt. \%) }\end{array}$ & $\begin{array}{l}\mathrm{T}_{1}^{\mathrm{a}, \mathrm{b}} \\
(\mathrm{h})\end{array}$ & $\begin{array}{l}\mathrm{T}_{2}^{\mathrm{b}, \mathrm{c}} \\
(\mathrm{h})\end{array}$ & $\begin{array}{l}\mathrm{H}_{\text {rel }}{ }^{d} \\
(\%)\end{array}$ \\
\hline 0.1 & $7.7 \pm 1.3$ & $9.5 \pm 1.3$ & 46.5 \\
\hline 0.06 & $2.2 \pm 0.6$ & $4.5 \pm 0.6$ & 44.2 \\
\hline 0.03 & $2.9 \pm 0.4$ & $6.7 \pm 0.8$ & 43.9 \\
\hline 0.01 & $3.3 \pm 0.2$ & $11.4 \pm 0.9$ & 40.1 \\
\hline
\end{tabular}

\section{Kinetics of autoxidation}

Time-resolved FTIR spectroscopy was used for monitoring of the chemical changes on the alkyd films cured with $\mathbf{B z}_{1} \mathbf{F c}$. The spectra were measured both in transmission mode and by ATR technique. Considerably higher resolution of the transmission experiments, documented in Figure 4, enables to a detail inspection of developments in time while ATR technique is suitable for investigation of the thickness effect.

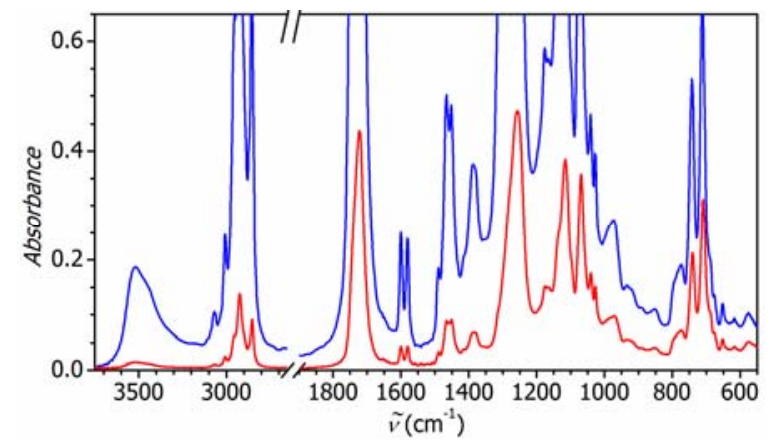

FIGURE 4 Infrared Spectra of Fresh Alkyd Resin S471 Measured in Transmission Mode (blue line; top) and by ATR Technique (red line; bottom).

Transmission experiments, performed on coatings of $100 \mu \mathrm{m}$ wet thickness, revealed main developments in regions $3650-2990 \mathrm{~cm}^{-1}$ and $1005-950 \mathrm{~cm}^{-1}$ as shown in Figures 5 and 6 , respectively. The raising band at $3430 \mathrm{~cm}^{-1}$ was assigned to $\mathrm{O}-\mathrm{H}$ stretching of hydroperoxide group appearing upon autoxidation process (Figure 5). ${ }^{12,36}$ Unfortunately, the vibration mode is not suitable for a detailed kinetic analysis since it is quite difficult to separate it from bands of other $\mathrm{OH}$-containing species (e.g. partially esterified phthalic acid and glycerol). Main difficulties are caused by broad bands of water $\left(3520 \mathrm{~cm}^{-1}, 3300 \mathrm{~cm}^{-1}\right),{ }^{12}$ which is formed as a side product of hydroperoxide decomposition (Figures 2 and 5). A sharp band at $3008 \mathrm{~cm}^{-1}$, which was assigned to $\mathrm{C}-\mathrm{H}$ stretching of cis- $\mathrm{CH}=\mathrm{CH}$ moiety, ${ }^{36}$ is more suitable for kinetic studies since it is well separated from vibration modes of the other $\mathrm{C}-\mathrm{H}$ containing 
moieties (Figure 5). The band decreases in intensity as the initial step of autoxidation proceeds. Appearing cis-trans-conjugated double bond moiety gives a band of medium intensity at $989 \mathrm{~cm}^{-1}$ (Figure 6), which was assigned to $\mathrm{C}-\mathrm{H}$ wagging. ${ }^{19}$ The band rises steeply at the beginning of the autoxidation proceeds but it reaches a maximum within few hours and then decreases slowly due to addition of present radicals $\left(\mathrm{R}^{\circ}, \mathrm{RO}^{\circ}, \mathrm{ROO}^{\circ}\right)$ on the conjugated double bond system. This process produces moiety with isolated trans-double bond, which can be followed in the spectra due to $\mathrm{C}-\mathrm{H}$ wagging band at $973 \mathrm{~cm}^{-1}$ (Figure 6). ${ }^{19}$ Evaporation of DMSO, which is used as a co-solvent, was monitored on bands at 952 and $933 \mathrm{~cm}^{-1}$. The transmission experiment on the coating of $100 \mu \mathrm{m}$ wet thickness reveals that it fully disappears from within $3 \mathrm{~h}$ after application (for details, see Supporting Information).

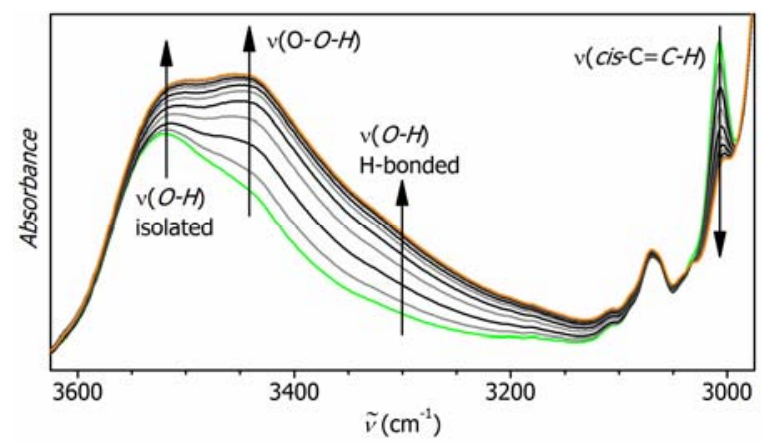

FIGURE 5 Developments in Region of O-H Stretching and C-H Stretching Bands. Green and Orange Line Represent the First and the Last Spectrum of the Series, Respectively.

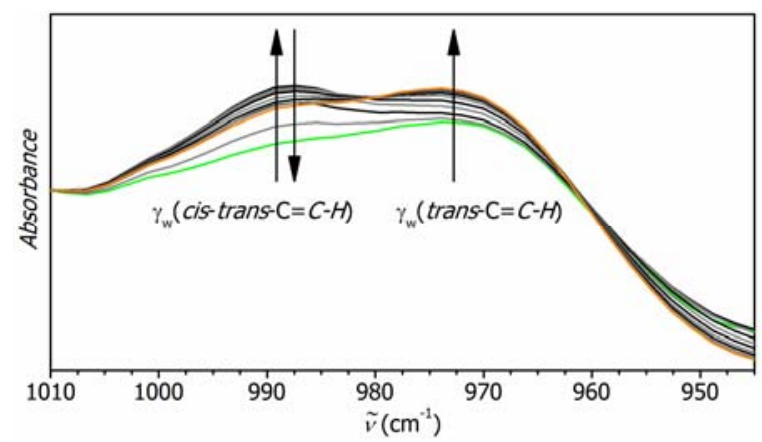

FIGURE 6 Developments in Region of C-H Bending Bands. Green and Orange Line Represent the First and the Last Spectrum of the Series, Respectively.

The kinetics of the autoxidation process was investigated in range of metal concentration 0.01-0.1 wt.\%. Initial phase of the process was followed by disappearance of band at $3008 \mathrm{~cm}^{-1}$, which correlates with a concentration of the active cis- $\mathrm{CH}=\mathrm{CH}$ moiety (Figure 2). Logarithmic plots of time development, shown 
in Figure 7, are linear up to about $50 \%$ conversion suggesting behavior of pseudo-first order. Such observation is fully in agreement with previous experiments, performed on liquid model systems, ${ }^{37}$ revealing that the alkyd coatings stay saturated with air-oxygen and liquid-like during this phase of curing. The estimated rate coefficients are highly concentration dependent.

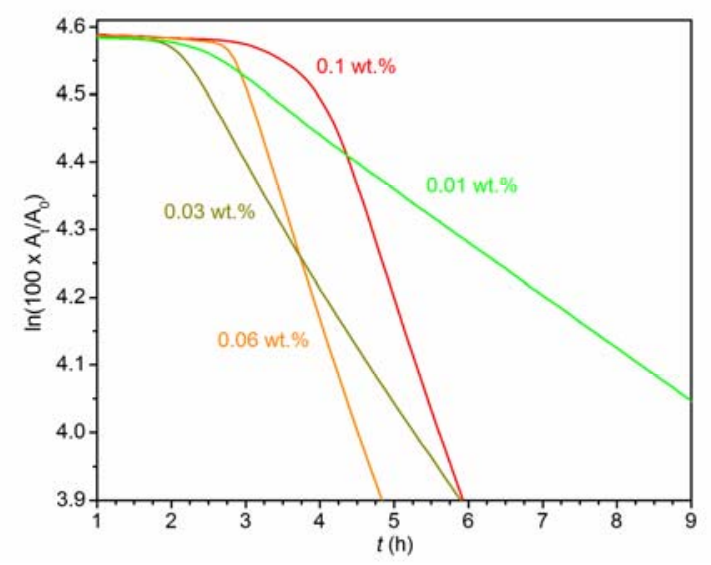

FIGURE 7 Time Dependent Integral Plots of the Band at $3008 \mathrm{~cm}^{-1}\left[\mathrm{v}_{\mathrm{a}}(c i s-\mathrm{C}=\mathrm{C}-\mathrm{H})\right]$ for the Formulations

\section{$\mathrm{Bz}{ }_{1} \mathrm{Fc} / \mathrm{S} 471$.}

In the range $0.01-0.06 \mathrm{wt} . \%$ of metal in dry matter content, the rate coefficients increase with increasing concentration. Nevertheless, the first sings of overdosing appear already at $0.06 \mathrm{wt} . \%$ as longer induction time (Table 2). Further increase of concentration do not give higher reaction rate but only to prolongation of the induction time. At concentration $0.1 \mathrm{wt} . \%$, the huge overdose effect is apparent from longer half-life of the reaction that well correlates with prolongation of drying times (Table 1). The overdose effect is caused by too high concentration of radicals that enhances probability of deperoxidation side reaction (eq. 1,2$).{ }^{38}$ We note that mutual termination of peroxyl radicals that may give ROOR crosslinks is less probable (eq. 2). Ratio of the reaction rates is 7-10: $1{ }^{39}$

TABLE 2 Kinetic Parameters of Autoxidation Process.

\begin{tabular}{lllll}
\hline $\begin{array}{l}\text { Metal } \\
\text { content } \\
(\text { wt.\% })\end{array}$ & $\begin{array}{l}-k_{\max }{ }^{\mathrm{a}} \\
\left(\mathrm{h}^{-1}\right)\end{array}$ & $\begin{array}{l}I T^{\mathrm{a}} \\
(\mathrm{h})\end{array}$ & $\begin{array}{l}t_{1 / 2^{\mathrm{a}}} \\
(\mathrm{h})\end{array}$ & $\begin{array}{l}t_{\text {conj }}{ }^{\mathrm{b}} \\
(\mathrm{h})\end{array}$ \\
\hline 0.1 & 0.34 & 3.9 & 5.9 & 7.4 \\
0.06 & 0.35 & 2.8 & 4.8 & 6.0 \\
0.03 & 0.20 & 2.1 & 5.9 & 7.9 \\
0.01 & 0.09 & 2.4 & 10.7 & 14.7 \\
\hline
\end{tabular}



a Maximum rate constant $\left(-k_{\max }\right)$, Induction time $(I T)$ and Half-life $\left(t_{1 / 2}\right)$ of autoxidation process. ${ }^{\mathrm{b}}$ Time, in which content of cis-trans
conjugated double bonds reached maximum.

$2 \mathrm{ROO}^{\bullet} \rightarrow 2 \mathrm{RO}^{\bullet}+\mathrm{O}_{2}$

$\mathrm{RO}^{\bullet}+\mathrm{ROOH} \rightarrow \mathrm{ROH}+\mathrm{ROO}^{\bullet}$

$2 \mathrm{ROO}^{\circ} \rightarrow \mathrm{ROOR}+\mathrm{O}_{2}$

Intensity of the band at $989 \mathrm{~cm}^{-1}$ correlates with content of cis-trans conjugated double bonds in the alkyd coatings. Its development in time is in Figure 8 for formulations with metal concentration 0.1-0.01 wt.\%. After induction time, the content of the conjugated double bonds rises as the hydroperoxides are formed. Maximum on the curves reveals the point, in which cross-linking reactions prevail over extensive peroxidation. At this time $\left(t_{\text {conj }}\right)$, more than $50 \%$ of substrate is consumed and the coatings become total dry. Only in case of overdosed formulation ( $0.1 \mathrm{wt} . \%)$, the coating is not tack-free dry $\left(t_{\text {conj }}\right.$ $<\tau_{1}$ ). Such observation implies that high concentration of the drier decelerates the peroxidation step but not the addition of radicals on double bond system.

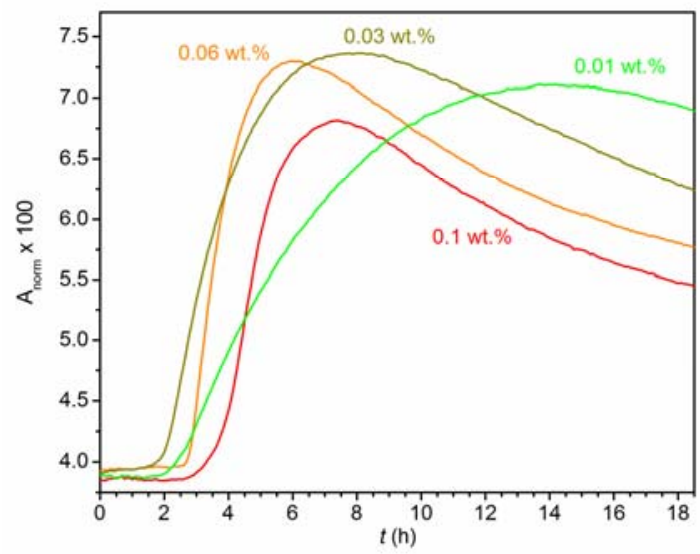

FIGURE 8 Developments of the Band at $989 \mathrm{~cm}^{-1}\left[\gamma_{w}(\right.$ cis-trans- $\left.C=C-H)\right]$ in Time for the Formulations $\mathrm{Bz}_{1} \mathrm{Fc} / \mathrm{S} 471$.

The formulation $\mathbf{B z}_{\mathbf{1}} \mathbf{F c} / \mathbf{S 4 7 1}$ of metal concentration 0.03 wt.\% was selected for investigation of thickness effects mainly because it does not show any signs of overdosing in aforementioned experiments. In contrary to transmission experiments, here applied ATR technique does not give averaged spectra from whole profile of the coating but only from thin layer at the coating/ATR crystal interface. Depth of penetration usually ranges between 0.1 and $10 \mu \mathrm{m}$ depending on the wavelength of infrared radiation, angle of incidence, and refractive index of coating and ATR crystal. ${ }^{40}$ In case of our all-reflective diamond crystal, depth of penetration is about $2 \mu \mathrm{m}$ at $1000 \mathrm{~cm}^{-1}$. When alkyd formulation is uniformly spread over the ATR crystal, this technique enables to follow the autoxidation process at exact depth under the 
surface. Series of experiments with different thickness of the coating then gives information about rate autoxidation process in the profile. Such samples were prepared by frame application of appropriate gap $(5-280 \mu \mathrm{m})$. The rate of autoxidation was followed on stretching band $\mathrm{v}_{\mathrm{a}}(\mathrm{cis}-\mathrm{C}=\mathrm{C}-\mathrm{H})$ at $3008 \mathrm{~cm}^{-1}$. Samples of 5-130 $\mu \mathrm{m}$ wet thickness exhibit virtually the same behavior as observed by transmission experiment on $100 \mu \mathrm{m}$ layer (Figure 9). Intensity of the band decreases steeply with short induction time suggesting negligible effect of oxygen diffusion. The first signs of deceleration of the autoxidation process are apparent at coating of $180 \mu \mathrm{m}$. Although the system behaves similarly as thicker ones during first two hours, the considerable decrease of reaction rate starts to be apparent at about $30 \%$ conversion. Nevertheless, the process seems to be enough fast to reach sufficient level of cross-linking within 24 hours. In thicker coatings, the autoxidation process is fully blocked at the coating/ATR crystal interface for more than $48 \mathrm{~h}$. Such observation reveals formation of a skin that is impenetrable by air oxygen. Wet thickness of the skin is about $150 \mu \mathrm{m}$ that corresponds to $40 \mu \mathrm{m}$ of a dry alkyd as determined by independent measurement on glass plate. Bellow the skin the autoxidation process does not start within $48 \mathrm{~h}$ after application.

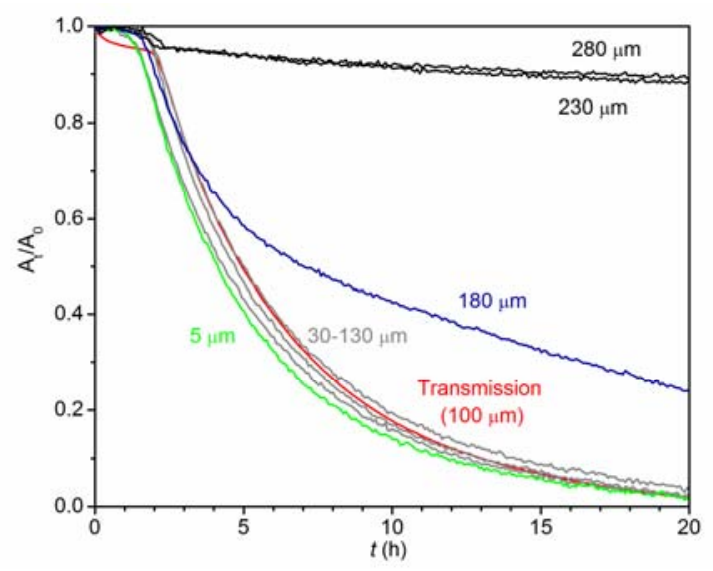

FIGURE 9 Developments of the Band at $3008 \mathrm{~cm}^{-1}\left[\mathrm{v}_{\mathrm{a}}(c i s-\mathrm{C}=\mathrm{C}-H)\right]$ for the Coatings $\mathrm{Bz}_{\mathbf{1}} \mathbf{F c} / \mathbf{S} 471$ (metal concentration 0.03 wt.\%) of Different Thickness.

\section{CONCLUSIONS}

This study gives a detailed description of chemical curing for alkyd formulations containing ferrocenebased catalyst. Performance of the catalyst was evaluated on prepared coatings using standard mechanic tests. Chemical changes of alkyd were studied in-depth by infrared spectroscopy. Such experiments offer determination of kinetic parameters of the autoxidation process in thin layer of the 
sample as well as effects of film thickness. The later approach, using ATR-technique, was used on alkyd coatings for the first time. Similarly as the Raman technique, it gives a direct information about chemical changes of alkyd formulation. As the sample is not irradiated with high energetic laser beam, the risk of light-induced initiation autoxidation process is eliminated. On common FTIR spectrometers with allreflective ATR, high-quality spectra could be collected each $\sim 2$ min. for days.

\section{REFERENCES AND NOTES}

1. Nelson, D. In Paint and Coating Testing Manual: 15th Edition of the Gardner-Sward Handbook; Koleske, J. V., Ed.; ASTM International: West Conshohocken, 2012, pp 65-71.

2. Hofland, A. Prog. Org. Coat. 2012, 73, 274-282.

3. Jones, F. N. In Ullmann's Encyclopedia of Industrial Chemistry, 2003, pp 429-446.

4. van Gorkum, R.; Bouwman, E. Coord. Chem. Rev. 2005, 249, 1709-1728.

5. Soucek, M. D.; Khattab, T.; Wu, J. Prog. Org. Coat. 2012, 73, 435-454.

6. Lison, D.; De Boeck, M.; Verougstraete, V.; Kirsch-Volders, M. Occup. Environ. Med. 2001, 58, 619-625.

7. De Boeck, M.; Kirsch-Volders, M.; Lison, D. Mutat. Res. 2003, 533, 135-152.

8. Bouwman, E.; van Gorkum, R. J. Coat. Technol. Res. 2007, 4, 491-503.

9. Oyman, Z. O.; Ming, W.; Micciche, F.; Oostveen, E.; van Haveren, J.; van der Linde, R. Polymer 2004, 45, 7431-7436.

10. de Boer, J. W.; Wesenhagen, P. V.; Wenker, E. C. M.; Maaijen, K.; Gol, F.; Gibbs, H.; Hage, R. Eur. J. Inorg. Chem. 2013, 3581-3591.

11. Pirš, B.; Znoj, B.; Skale, S.; Zabret, J.; Godnjavec, J.; Venturini, P. J. Coat. Technol. Res. 2015, 12, 965-974.

12. Křižan, M.; Vinklárek, J.; Erben, M.; Císařová, I.; Honzíček, J. Prog. Org. Coat. 2017, 111, 361-370.

13. Erben, M.; Veselý, D.; Vinklárek, J.; Honzíček, J. J. Mol. Catal. A: Chem. 2012, 353-354, 13-21.

14. Preininger, O.; Vinklárek, J.; Honzíček, J.; Mikysek, T.; Erben, M. Prog. Org. Coat. 2015, 88, 191198.

15. Preininger, O.; Honzíček, J.; Kalenda, P.; Vinklárek, J. J. Coat. Technol. Res. 2016, 13, 479-487.

16. Preininger, O.; Charamzová, I.; Vinklárek, J.; Císařová, I.; Honzíček, J. Inorg. Chim. Acta 2017, 462, 16-22.

17. Muizebelt, W. J.; Hubert, J. C.; Venderbosch, R. A. M. Prog. Org. Coat. 1994, 24, 263-279.

18. Muizebelt, W. J.; Donkerbroek, J. J.; Nielen, M. W. F.; Hussem, J. B.; Biemond, M. E. F.; Kloosen, R. P.; Zobel, K. H. J. Coat. Technol. 1998, 70, 83-93.

19. Oyman, Z. O.; Ming, W.; van der Linde, R. Prog. Org. Coat. 2003, 48, 80-91.

20. Dubrulle, L.; Lebeuf, R.; Thomas, L.; Fressancourt-Collinet, M.; Nardello-Rataj, V. Prog. Org. Coat. 2017, 104, 141-151.

21. Ellis, G.; Claybourn, M.; Richards, S. E. Spectrochim. Acta 1990, 46A, 227-241.

22. Sturdy, L. F.; Yee, A.; Casadio, F.; Shull, R. Polymer 2016, 103, 387-396.

23. Marton, B.; van der Ven, L. G. J.; Otto, C.; Uzunbajakava, N.; Vancso, J. V. Polymer 2005, 46, 11330-11339.

24. Oyman, Z. O.; Ming, W.; van der Linde, R.; ter Borg, J.; Schut, A.; Bieleman, J. H. Surf. Coat. Int. B Coat. Trans. 2005, 88, 269-275.

25. Erich, S. J. F.; van der Ven, L. G. J.; Huinink, H. P.; Pel, L.; Kopinga, K. J. Phys. Chem. B 2006, 110, 8166-8170. 
26. Gezici-Koc, Ö.; Thomas, C. A. A. M.; Michel, M. E. B.; Erich, S. J. F.; Huinink, H. P.; Flapper, J.; Duivenvoorde, F. L.; van der Ven, L. G. J.; Adan, O. C. G. Mater. Today Commun. 2016, 7, 22-31.

27. Kalenda, P.; Holeček, J.; Veselý, D.; Erben, M. Prog. Org. Coat. 2006, 56, 111-113.

28. Štáva, V.; Erben, M.; Veselý, D.; Kalenda, P. J. Phys. Chem. Solids 2007, 68, 799-802.

29. Lu, B.; Wang, Q.; Zhao, M.; Xie, X.; Zhang, Z. J. Org. Chem. 2015, 80, 9563-9569.

30. ASTM D5895-03, Standard Test Methods for Evaluating Drying or Curing During Film Formation of Organic Coatings Using Mechanical Recorders; ASTM International: West Conshohocken, PA, 2003.

31. Micciche, F.; Oostveen, E.; van Haveren, J.; van der Linde, R. Prog. Org. Coat. 2005, 53, 99-105.

32. ISO 1522:2006, Paints and varnishes - Pendulum damping test; International Organization for Standardization, 2006.

33. Persoz, B. Peintures, Pigments, Vernis 1945, 21, 194-201.

34. Martí, M.; Molina, L.; Alemán, C.; Armelin, E. ACS Sustainable Chem. Eng. 2013, 1, 1609-1618.

35. Norlin, L. H. In Ullmann's Encyclopedia of Industrial Chemistry, 2000, pp 1-14.

36. van de Voort, F. R.; Ismail, A. A.; Sedman, J.; Emo, G. J. Am. Oil Chem. Soc. 1994, 71, 243-253.

37. Warzeska, S. T.; Zonneveld, M.; van Gorkum, R.; Muizebelt, W. J.; Bouwman, E.; Reedijk, J. Prog. Org. Coat. 2002, 44, 243-248.

38. Spier, E.; Neuenschwander, U.; Hermans, I. Angew. Chem. Int. Ed. 2013, 52, 1581-1585.

39. Hiatt, R.; Clipshan, J.; Visser, T. Can. J. Chem. 1964, 42, 2754-2457.

40. Smith, B. C. In Fundamentals of Fourier Transform Infrared Spectroscopy, Second Edition; CRC Press, 2011, pp 129-146. 
GRAPHICAL ABSTRACT

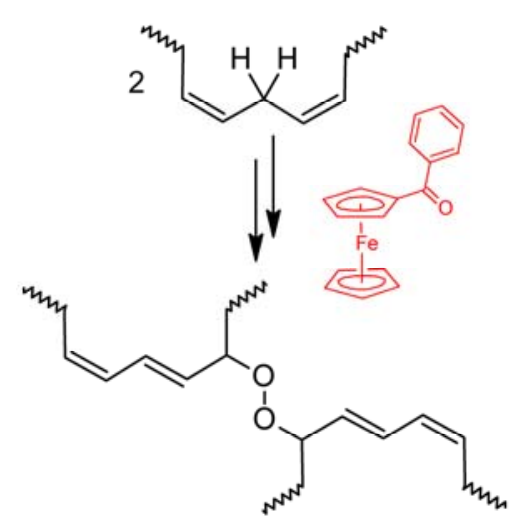

